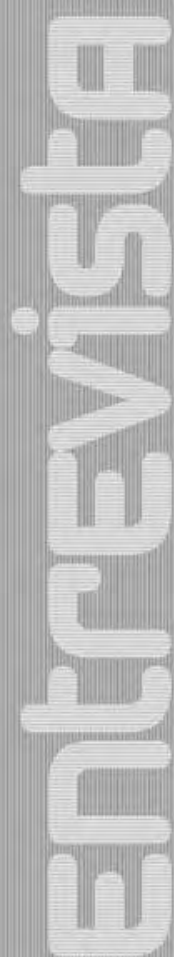





\section{Ser Cubano' (entrevista com Tania Bruguera)}

por RoseLee Goldberg

RoseLee Goldberg é diretora fundadora da Performa, organização situada em Nova York e dedicada aos estudos da performance na história da arte do século XX. Como historiadora da arte, crítica e curadora, RoseLee Goldberg tem organizado exposições, performances e seminários na Royal College of Art Gallery em Londres, The Kitchen, no Museum of Modern Art e no Guggenheim Museum, os quais estabeleceram importantes precedentes no campo da performance. O livro seminal de RoseLee Goldberg, Performance Art from Futurism to the Present (1979 \& 2000), a primeira obra dedicada à história da arte da performance, foi traduzido em seis línguas e é usado internacionalmente como livro chave para o ensino da performance nas universidades. RoseLee Goldberg é professora da New York University desde 1987 e é frequente colaboradora da Artforum. Dentre seus livros estão Performance: Live Art Since 1960 e Laurie Anderson.

Tania Bruguera nasceu em Havana, Cuba, em 1968, filha de Miguel Bruguera, conselheiro político cubano na Embaixada de Cuba em Paris e embaixador no Líbano e no Panamá, e de Argelia Fernandez, tradutora de espanhol-inglês com bacharelado em Ciências Sociais. Tania Bruguera estudou no Liceu Francês durante sua infância e, dos 12 anos em diante, em uma escola de arte em Havana, se graduando pelo Instituto Superior de Arte em 1992.

Nos últimos sete anos [1998 a 2005] ela tem vivido em Chicago e em Havana, dividindo o ano entre duas cidades, duas culturas e duas ideologias, "entre passado e futuro", como ela disse. Essas idas e vindas entre continente e ilha, intercaladas com extensas viagens internacionais, têm aguçado o entendimento de Bruguera sobre o que significa "ser cubano" e o 
que é necessário para realizar uma obra que seja relevante tanto localmente quanto internacionalmente.

"Posso utilizar o mesmo modelo dentro e fora de Cuba?" - ela se questiona. Sua consciência de viver em uma animada matriz política, de consequências ligadas a ações, proporciona a bússola ética à obra de Bruguera. Esse também foi o foco de nossa conversa que começou no último janeiro na Cidade do México e continuou em Miami e em Nova York. ${ }^{2}$

RoseLee Goldberg: Em nossa última conversa, você falou sobre o impacto emocional da política para além de sua influência intelectual ou ideológica. Eu achei sua noção de "política como sedução" interessante, especialmente considerando que várias de suas obras se referem à tortura ou repressão ou censura, ações que alguns associam com medo e repulsa, não sedução.

Tania Bruguera: Crescendo em Cuba, eu entendi que os melhores políticos trabalham com as emoções porque eles sabem que essa é a melhor ferramenta para manipular as pessoas. O poder político lida exatamente com a manipulação e com o controle das pessoas para conseguir o que eles querem. Manipular emoções é uma forma sedutora de atingir aquele fim.

RoseLee Goldberg: Você pode descrever uma de suas obras que seja manipuladora nesse sentido?

Tania Bruguera: Aquela que fiz em Havana (Sem título (Havana, 2000)) é a mais bem sucedida em assustar, seduzir e surpreender o observador. É um trabalho narrativo que primeiramente atrai a audiência a um espaço bonito (uma antiga fortaleza em Havana) e depois os assusta um pouco porque, uma vez que se está dentro, é muito escuro. Os visitantes caminham em uma superfície muito macia e suave (cana de açúcar seca) em direção a uma luz brilhante embutida no teto, que eles logo descobrem ser um monitor de televisão em preto e branco mostrando imagens de Fidel Castro proferindo um discurso em uma competição de natação no mar. Eles vão em direção à luz e a luz é Fidel! E gradualmente, enquanto suas visões se acostumam com a escuridão, eles notam que nas proximidades há vários cubanos nus e a conclusão é, "Oh meu Deus, eu fui tão seduzido pelo poder que nem mesmo percebi o que se passava ao meu redor." 


\section{Tania Bruguera}

Untitled (Havana, 2000), 2000

cana de açúcar moída, monitor de vídeo, DVD player

(Fonte: http://www.artesmagazine.com/2010/03/) 
Quero que meus trabalhos sejam cada vez mais sobre esse tipo de experiências. Sentindo as obras, não apenas olhando-as. Eu quero que as pessoas se movam emocionalmente através de minha obra. Eu trabalho com emoções e memória, e com a ideia de documentar não em um sentido histórico, mas através de emoções.

Quero que minha obra seja transformada e lembrada pela audiência como uma experiência emocional. Quero que a audiência acesse as obras como uma experiência, às vezes uma experiência física, e leve a "documentação" disso com eles como sua própria memória viva. Eu gostaria que meu trabalho não fosse visto, mas lembrado.

\section{RoseLee Goldberg: Que outras emoções guiam o seu trabalho?}

Tania Bruguera: Eu gosto de trabalhar com o medo porque, quando as pessoas sentem medo, elas ficam mais conscientes, elas ficam alerta. Elas começam a usar outros meios para compreender o que está acontecendo. Gosto das pessoas em alerta quando elas veem minha obra. Medo também é um caminho para aprender e, uma vez que saibamos como lidar com o medo, podemos ser livres.

RoseLee Goldberg: Você já experimentou medo real?

Tania Bruguera: Provavelmente já, mas nada que fosse físico ou ameaça de morte.

RoseLee Goldberg: Quando criança, você viveu em várias cidades onde havia tensão política real, quando seu pai era o embaixador cubano no Líbano nos anos 1970 e no Panamá durante a invasão americana, por exemplo.

Tania Bruguera: Na verdade, agora que você pergunta, acho que o medo tem estado presente em minha vida, mas de forma sutil. Nunca foi um medo extremo, mas talvez um medo que vinha com a percepção de que o que você faz terá consequência na vida de outras pessoas, consequências que você não controla. Foi o que aconteceu quando fiz um jornal, Memory of the Post-War, 1993/1994, que era uma peça de arte que parecia um "jornal de arte", mas editado como um jornal comum. Convidei artistas para escreverem seções típicas sobre esporte ou agricultura, como uma metáfora da situação política e artística de Cuba naqueles tempos. Fui chamada ao Conselho de Arte e me foi dito para destruir o jornal; um amigo que me ajudou 
com essa obra foi detido e a pessoa que a imprimiu foi demitida. Isso foi muito perturbador, traumatizante. Eu parei de trabalhar por um longo tempo depois disso. Esse incidente foi a origem da série "obra do cordeiro" (The Burden of Guilt, 1997-1999) quando usei carcaças de cordeiro ao redor de meu pescoço e comi terra. Senti que tinha um compromisso e, ao mesmo tempo, estava preocupada sobre como alguém poderia continuar a trabalhar sob aquelas circunstâncias. Submissão era uma forma de sobrevivência. "Devo me curvar às demandas deles ou fazer meu próprio trabalho?" O jornal foi uma obra hiper-realista. Não porque se parecia com um jornal, mas porque funcionou como um.

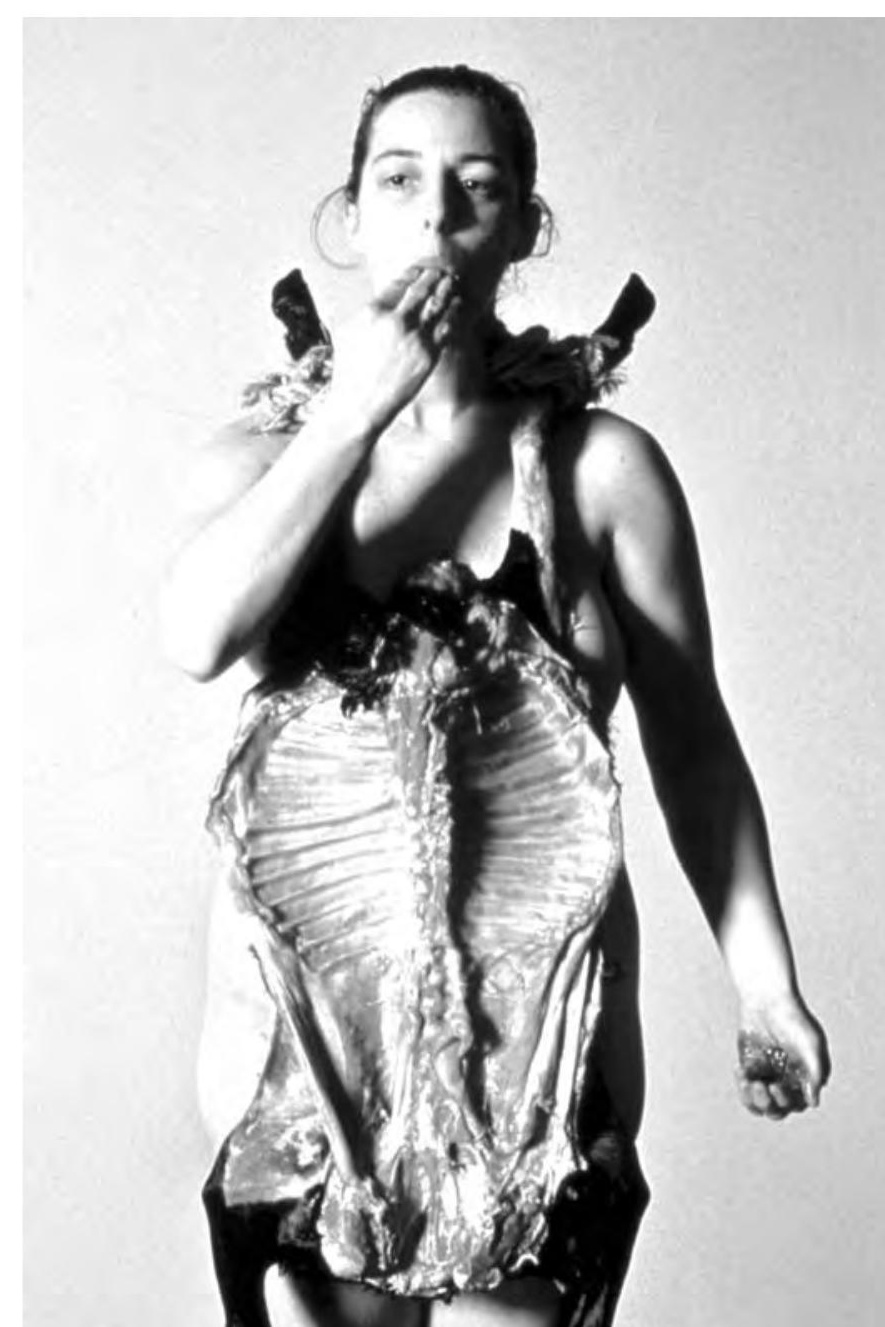


RoseLee Goldberg: O que você quer dizer?

Tania Bruguera: Eu quero trabalhar com a realidade. Não com a representação da realidade. Não quero que minha obra represente algo. Não quero que as pessoas olhem para o trabalho, mas que estejam nele, às vezes mesmo sem saber que se trata de arte. Isso foi uma situação real. O jornal foi impresso em uma gráfica na qual se produz jornais diariamente e circulou como um jornal. E ele teve um impacto. Algo aconteceu. Ele foi comentado por pessoas que não sabiam nada sobre arte. Eu tinha uma tia no Partido Comunista que uma vez me telefonou e me disse: "O que você fez?" Ela estava muito preocupada porque meu jornal havia sido discutido em uma reunião do partido. O fato de ele ter entrado na sociedade ampliada, não como uma obra de arte, mas como um evento, um gesto, tornou-o hiper-real.

RoseLee Goldberg: Para realizar seus trabalhos em Cuba nos anos 1980-90, você tinha que estar consciente de estar sendo vigiada.

Tania Bruguera: Sim, isso era um fato. A ideia era fazer gestos públicos. Quando eu tinha 15 ou 16 anos, já estava estudando arte e o mundo da arte em Cuba era muito ativo com um verdadeiro movimento de vanguarda. Fui muito influenciada por eles. Aquele grupo de artistas foi posteriormente chamado de "La Generación de los Ochenta" (A Geração dos Oitenta). Ela inclui Flavio Garciandia, Glexis Novoa, Carlos Cárdenas, Lázaro Saavedra, José Angel Toirac, Arte Calle, dentre muitos outros. Na verdade, essa é a influência real e mais importante no meu trabalho, não Marina Abramovic ou Vito Acconci como as pessoas afirmam, mesmo que esses sejam os artistas de performance com os quais as pessoas estejam mais familiarizadas; eu nem mesmo sabia sobre sua existência naquele tempo. Minha influência, o que realmente impactou minhas ideias sobre arte e sobre a maneira como quero fazer meu trabalho foi "A Geração dos Oitenta", esse excitante grupo de artistas, fazendo pintura, escultura, ações e happenings me fez ver a arte como um gesto com conotações sociais. Quando o grupo deixou Cuba em consequência da censura e da pressão política, uma onda de arte muito diferente, mais comercial, metafórica e representacional tomou seu lugar. Eu desejava ardentemente o tipo de gestos públicos que eles haviam produzido e o jornal foi para mim uma forma de continuar aquelas ideias. 
RoseLee Goldberg: Qual a diferença entre uma performance e um gesto?

Tania Bruguera: Para mim, um gesto é mais sobre a intenção do trabalho. É mais sobre o cotidiano. Um gesto é sobre repetir uma ação do cotidiano e colocá-la em um espaço consciente. O gesto cria uma atmosfera. Eu também prefiro o termo arte de conducta (traduzido livremente como "arte comportamental") ao termo performance, especialmente em espanhol, porque conducta em espanhol significa "conduzir" ou "ser conduzido". Também significa "comportamento", como em maneiras sociais, assim como "comportamento" em um sentido mais fisiológico. Então, para mim, a arte da performance começa como um gesto, como uma forma de comportamento. Foi o que os futuristas e os dadaístas fizeram no início dos anos 1900. O trabalho deles foi uma resposta a um momento específico. Arte de conducta acontece quando a descrição do gesto carrega a ideia de obra, quando narrar a obra é a ação e a descrição da obra é a obra. Função é parte da obra. O espaço entre ser considerada arte ou não tem sido tensionado. São obras que acontecem fora do mundo da arte e não sob os valores do mundo da arte, mas posteriormente elas circulam como obras de arte no mundo da arte através de documentação ou de rumores. Rumor é precisamente a forma de documentação dessas obras. São obras que são lembradas, não vistas, lembradas como nenhum outro evento é na vida das pessoas que delas participaram. Nessas obras, o corpo é o corpo social. Elas criam uma atmosfera não um objeto.

RoseLee Goldberg: Eu gostei do que você disse a respeito dos gestos criando uma atmosfera.

Tania Bruguera: Nos anos 1960 e 1970, as pessoas faziam arte comportamental. Para mim, Adrian Piper é uma artista comportamental, porque muito de sua obra é sobre o gesto, como na obra em que ela distribui cartões a pessoas, anunciando sua identidade étnica ou aulas de dança, esses gestos, por sua vez, criaram uma atmosfera. Ou mais recentemente, Francis Alÿs caminhando pelas ruas da Cidade do México com uma arma na mão e à vista. Mas quando a performance entra na galeria e os observadores se sentam para assisti-la, a obra é "objetificada". O corpo se torna objetificado e a performance se afasta de ser sobre gesto. Eu quero voltar ao começo! Eu sempre amei o Dada, eles estavam fazendo "arte de reação" e eles foram "artistas do gesto". 
RoseLee Goldberg: Mas como alguém faz esses gestos atualmente? Você não pode ter aquele tempo de volta.

Tania Bruguera: Quando reconstruí uma performance de Ana Mendieta pela primeira vez em 1986, para mim aquilo foi um gesto, uma peça comportamental, porque era sobre reação ao momento político daquela época. Posteriormente, quando fiz o jornal foi um gesto em resposta a um momento político diferente, que para mim era o vazio deixado pelo ativismo social da "Geração dos Oitenta". Acho que comecei na linha certa com as obras de "arte comportamental", mas depois fui deslocada dessa linha pela forte reação ao jornal. Comecei a fazer performances mais tradicionais, que se tornaram mais objetificadas. No momento atual, não faço mais performances, pelo menos não daquela forma. Minhas novas performances são feitas quando viajo de avião ou quando faço palestras. As palestras são sobre os diferentes aspectos da performance. Uma é sobre documentação, outra é sobre a relação entre política e arte, a outra é sobre o uso de valor de choque em performances. A última que fiz foi sobre vulnerabilidade e performance.

RoseLee Goldberg: Isso será gravado?

Tania Bruguera: Sim, porque esse é o padrão de documentação de palestras. Palestras não são sobre experiência. Elas são sobre transmissão de conhecimento.

RoseLee Goldberg: Que outras “não-performances" você está considerando?

Tania Bruguera: Eu cancelei minha exposição individual no dia e na hora da abertura; no restante do tempo no qual a exposição deveria estar aberta à visitação, a galeria estava vazia e fechada. Agora estou trabalhando em uma obra sobre Cuba, inspirada por uma obra realizada no início dos anos 1990 pelo coletivo cubano Los Carpinteros. A obra foi chamada Se vende tierra de Cuba (Terra cubana à venda) e isso era, eu não lembro exatamente, acho que uma caixa de madeira, do tipo baú de tesouros, com terra e o título de obra. Quero levar a obra adiante. Proponho vender pedaços de Cuba no mercado de ações. Estou no processo de criar uma corporação que venderá duas coisas: metros quadrados reais e o conceito de Cuba como utopia e todas as ideias projetadas que as pessoas têm sobre Cuba como um valor a ser ven- 
dido. Os lucros voltarão diretamente para Cuba e meu papel será o de atuar como condutora dessa transação. Utilizarei meu prestígio para ser uma mediadora. É uma obra site-specific que somente pode ser feita fora dos Estados Unidos e será exibida ou "ativada" pela primeira vez neste outono em uma exposição coletiva no Canadá. É também uma obra site-specific uma vez que ela depende e será afetada por condições históricas e sociais particulares.

RoseLee Goldberg: Achei interessante que várias das obras sobre as quais temos discutido recentemente se relacionam diretamente a Cuba. Nós conversamos antes sobre sua recriação da obra de Ana Mendieta como uma forma de trazê-la de volta a Cuba. Depois de alguns anos vivendo e trabalhando internacionalmente, agora você está trazendo Tania de volta a Cuba?

Tania Bruguera: Eu nunca parti. Mas estou trazendo de volta a Cuba uma ideia de Cuba que as pessoas de fora possuem sobre o país.

RoseLee Goldberg: Por exemplo?

Tania Bruguera: Os preconceitos e preconcepções sobre Cuba. A ideia surgiu quando eu estava vivendo em Cuba, como um comentário sobre muitos estrangeiros chegando à ilha e esperando instalar seus negócios antes que Castro morresse, de maneira que pudessem tirar vantagem das mudanças quando ocorressem. Mas vivendo em Chicago e em Havana, tenho tido que enfrentar percepções externas de Cuba, desde a ira de uma geração antiga de cubanos vivendo em Miami à idealização de Cuba pelos esquerdistas. Eu quero trabalhar com esse espectro amplo e diversificado de percepções do país.

RoseLee Goldberg: Então, por um lado você está examinando uma gama de percepções sobre Cuba tanto externas quanto internas. E você também está falando sobre sua experiência de artista nesses dois ambientes.

Tania Bruguera: Sim, estou trabalhando com questões e sentimentos cubanos, mas estou fazendo-o em uma língua dominante. Ou talvez seja uma "língua internacional" que vem do que chamam de "artista internacional." Eu me vejo em uma encruzilhada e estou tendo muitos problemas com isso. Por quê? Porque tenho visto muitas pessoas que não nasceram na Eu- 
ropa ou em centros hegemônicos de arte como Nova York ou Londres. Eles são vistos como artistas "locais", como artistas "originais", mas depois de um ou dois eventos internacionais, eles começam a se tornar artistas 'internacionais." Eu penso que essa é uma transição muito perigosa porque muitas pessoas se tornam formalistas, de certa maneira. Quando você fala sobre seu próprio ambiente "local," você está reagindo a tudo ao redor de você. Mas então, você precisa traduzir aquelas reações em uma linguagem que todos entendam e no processo você perde muitos detalhes. Você começa falando tão vagamente que acaba não falando absolutamente nada.

RoseLee Goldberg: Como você está trabalhando com isso?

Tania Bruguera: Estou tentando ver o quão diferentes as obras podem se tornar de um lugar para outro. Por exemplo, a obra que fiz em Documenta Sem título (Kassel, 2002) foi uma tradução de Sem título (Havana, 2000), a obra que fiz na fortaleza. Não foi uma tradução formal, mas a tradução de um tema: o que vemos e o que não vemos, o que queremos ver e o que não queremos ver. Era sobre responsabilidade. Eu tenho uma [obra], da mesma série, que quero fazer um dia em Israel, chamada Sem título (Haifa, 2003). Ou o trabalho que fiz depois da residência na Índia com milhares de sacos de chá, Justiça poética. Considero essas instalações como intensos testes para ser uma artista "internacional." Estou tentando ver como posso falar em uma linguagem que todos entenderão, tentando achar conexões ao lidar com questões que são muito específicas à minha origem e aos meus interesses. Também estou muito consciente de não ser "exotizada", de não fazer um trabalho que atrairá atenção somente por ser "cubano". Estou lutando com essas contradições. 


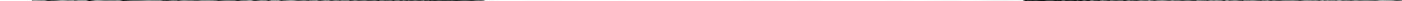


RoseLee Goldberg: Provavelmente alguns têm a expectativa de que você sempre irá se referir a Cuba de alguma forma, devido à sua história.

Tania Bruguera: De qualquer forma, é uma situação complicada. Cuba não é mais minha realidade cotidiana e, muitas vezes, sinto que não tenho mais o direito de falar certas coisas sobre Cuba. Não tenho o mesmo acesso ao processo de mudança de sensibilidades. Talvez a obra sobre vender Cuba seja mais sobre onde eu me encontro neste exato momento, que é no meio, entre este mundo e aquele mundo.

Abril 2005.

Tradução: Caroline Alciones e Luiz Sérgio de Oliveira

\section{Notas}

1 N. dos T.: Traduzido da versão disponível na página oficial da artista Tania Bruguera <http://www.taniabruguera.com/>. Originalmente a entrevista foi publicada em GOLDBERG, RoseLee. Interview II, Tania Bruguera, La Bienale di Venezia, ed. Prince Claus. Chicago: Lowitz and Son, 2005, p. 11-21. (ISBN 0-9769449-01)

2 N. dos T.: A entrevista de RoseLee Goldberg com Tania Bruguera foi publicada em duas partes. Esta tradução se ocupa da segunda parte - Ser Cubano. A primeira - Regarding Ana - também está disponível na página oficial da artista. 